\title{
Survival Outcome in Patients with Bilateral Gross Renal Parenchymal Impairment detected by Tc-99m DTPA Renogram

\author{
${ }^{1}$ Azmal Kabir Sarker, ${ }^{2}$ Sharmin Reza, ${ }^{2}$ Shamim MF Begum, ${ }^{3}$ Monsurul Hoq, ${ }^{2}$ Zeenat Jabin, \\ ${ }^{2}$ Rahima Pervin, ${ }^{2}$ Nasreen Sultana, ${ }^{1}$ Sayeedul Alam and ${ }^{2}$ Raihan Hussain \\ ${ }^{1}$ Institute of Nuclear Medicine and Allied Sciences, BAEC, Beach Sand Minerals Exploitation Centre campus, Kolatoli, Cox's Bazaar, 2224 \\ ${ }^{2}$ National Institute of Nuclear Medicine and Allied Sciences, BAEC, Bangabandhu Sheikh Mujib Medical University campus, Shahbag, Dhaka, 1000 \\ ${ }^{3}$ Biostatistician, Murdoch Children's Research Institute, Melbourne, Australia \\ Correspondence Address: Azmal K Sarker, Institute of Nuclear Medicine and Allied Sciences, Cox’s Bazaar, aksninmas@gmail.com
}

\begin{abstract}
Introduction: Bilateral gross renal parenchymal impairment (GPI) is a term often used in nuclear imaging to describe severe diffuse glomerular dysfunction obtained with renal scan using Tc-99m diethylene triamine penta-acteic acid (Tc99m DTPA renogram). Whether bilateral GPI found on Tc99m DTPA renogram has any significance on the survival outcome of the patients has not been studied in Bangladesh.

Purpose: The study was carried out with the purpose of obtaining a sketch of short-term survival outcome in patients diagnosed with bilateral GPI at National Institute of Nuclear Medicine and Allied Sciences (NINMAS), a tertiary level institute.
\end{abstract}

Method: Nuclear imaging data of patients who had Tc-99m DTPA renogram from January 2013 to June 2013 at NINMAS were obtained from the divisional archive. Total number of patient who underwent the procedure within this period were examined and only those patients with definite diagnosis of bilateral GPI on renal scan were selected for final analysis. Telephone interview was conducted in the year 2015 to obtain the clinical follow-up data of patients with bilateral GPI.

Results: In the six months period from January 2013 to June 2013, there were 576 patients who had Tc-99m DTPA renogram. Out of these, 21 patients $(M / F=15 / 6)$ with mean age $45 \pm 20.9$ ( 3 months to 71 years) were diagnosed to have bilateral GPI. Follow up data of 16 $(M / F=12 / 4)$ patients with mean age $41.2 \pm 22.3$ ( 3 months to 65 years) were available. Eleven $(68.8 \%)$ patients were alive at the time of follow up and five $(31.2 \%)$ patients were found deceased. Deaths in all were reported to be associated with renal failure and occurred during hospital management. In this patient group, one and two year survival was estimated to be 93.8 and $68.8 \%$.

Conclusions: This study is expected to initiate in-depth assessment of survival pattern in kidney diseases in Bangladesh through future research.

KEY WORDS: Survival, gross parenchymal impairment, renal impairment, Tc-99m, DTPA.

\section{INTRODUCTION}

Renal scan using Tc-99m labeled diethylene triamine pentaacetic acid (Tc-99m DTPA renogram) is a sensitive technique for evaluation of renal functional impairment that are manifested either as Acute Kidney Injury (AKI) or Chronic Kidney Disease (CKD). Irrespective of underlying pathology, both AKI and CKD may show features of unilateral or bilateral mild, moderate or gross renal parenchymal impairment on a Tc-99m DTPA renogram. Diffuse severe impairment of renal function results in poor perfusion and uptake followed by negligible excretion of radiotracer in both kidneys producing a flattened time-activity curve, popularly known as gross renal parenchymal impairment (GPI), observed as a surrogate of severe forms of both AKI and CKD.

Patients with AKI have mortality of more than 50\% (1, 2) and up to $31 \%$ survivor of AKI progress to CKD

(3). The 2013 annual USA data report shows that patients with CKD had an adjusted mortality rate of up to 3.8 times greater than that in patients without CKD depending on stage (4) while the survival at five years was as low as $18 \%$ depending on presence of other comorbidities (5). In addition kidney diseases consume a staggering proportion of healthcare resources (6) and cause decline in quality of life $(6,7,8)$. Kidney disease is not reported among the top four contributors of mortality in Bangladesh (9) 
nevertheless it has a deleterious effect on quality of life while the high expense (10) of its management drains the patient economically. It is estimated that about 17-18 million of the adult population in Bangladesh suffers from kidney disease every year $(11,12,13)$. Statistics regarding survival rates among patients with CKD or ESRD in Bangladesh are too sparse and not sufficient enough to form a reference database.

The aim of the study was to assess the short-term survival outcome after nuclear imaging diagnosis of bilateral GPI in a selected group of patients referred to National Institute of Nuclear Medicine and Allied Sciences (NINMAS).

\section{METHODS}

\section{Subjects}

This is a cross sectional retrospective study conducted in the year, 2015 on a group of 576 patients (357 males, 219 females); who were referred to Nuclear Nephrology Division of NINMAS for evaluation of renal function. Of the total number of 576 cases, 21 patients were diagnosed with GPI based on Tc-99m DTPA renogram. Bilateral GPI was diagnosed when there was poor perfusion, negligible uptake as well as negligible washout of tracer resulting in a flat time-activity curve. Thus 21 patients who had features of GPI on Tc-99m DPTA renogram were selected in the final analysis.

\section{Procedure}

Patient data was obtained from the Nuclear Nephrology Divisional archive of patient studies. The image record file of all patients who underwent Tc-99m DTPA renogram from January to June 2013 were selected. Relevant investigations together with the Tc-99m DTPA renogram were noted. All patients who had been diagnosed as cases of bilateral GPI from the findings of Tc-99m DTPA renogram from January 2013 to June 2013 were selected and their contact information was retrieved. The contact numbers of patients were called up by two physicians in order to conduct a semi structured interview over telephone. Physicians could talk either directly with the patients or with a family member of a deceased patient. Information regarding improvement or decline of patient's quality of life in comparison to two years past status was obtained. Mode of managements within these two years was enquired. Serum creatinine level within last six months was noted. If the patient was reported as dead by a family member, they were asked to provide the date and place of death. They were also asked to provide hospital's comment about cause of death if it was a case of death in hospital.

\section{Variables and analytic method}

Quantitative variables were expressed appropriate summary statistics i.e. using mean \pm standard deviation (SD) and value ranges or median and interquartile range (IQR). The results of the qualitative variables are given as percentages. The time from the diagnosis of bilateral GPI to death or the date on which the data were censored was analyzed with the Kaplan-Meier method. In the survival analysis only death was considered as final event. Events were taken into account until 30 June 2015, the date the study ended. Associations of outcome with age, gender, or modes of management were not evaluated due to small size of sample. SPSS software version 20 (SPSS Inc., Chicago, IL, USA) was used for the statistical analyses. A $p$ value of 0.05 was considered to indicate statistical significance. Standard error (SE) and 95 percent confidence intervals (CI) are provided when relevant.

\section{RESULTS}

\section{Demographic Characteristics of the selected group of patients}

From January to June 2013, a total of 21 out of 576 (3.6\%) patients aged 3 months to 71 years were diagnosed to have bilateral GPI by Tc-99m DTPA renogram. Among them 15 were male and six were 
female. Mean age for these patients was $45 \pm 20.9$ years. Except for three (3 months, 4 and 7 years) patients all were adults (19 - 71 years). In July 2015 when the follow up telephonic interviews were conducted follow up data of 16 out of 21 (76\%) patients who were diagnosed as cases of bilateral GPI by Tc99m DTPA renogram from January to June 2013 were available. Thus, 16 patients were followed for a median period of 25.5 months. Among them 12 were male and four were female. Mean age for these patients were $41.2 \pm 22.3$ years ( 3 months to 65 years) SE 5.56, CI 29.3-53.05. The median age was 47.5 years, IQR 38 . Except for three ( 3 months, 4 and 7 years) patients all were adults ( $19-65$ years).

\section{Clinical Characteristics of the selected group of patients}

Among 16 patients, indications for referral to perform a Tc-99m DTPA renogram was bilateral moderate to gross hydronephrosis in two patients, nephrotic syndrome in one patients and abnormal ultrasound viz. bilateral small \& echogenic kidneys with lost corticomedullary differentiation in 13 patients. All patients $(n=16)$ had elevated levels of serum creatinine. Mean level of serum creatinine during Tc-99m DTPA renogram was $2.96 \pm 1.9$ $\mathrm{mg} / \mathrm{dl}(1.6-7.5 \mathrm{mg} / \mathrm{dl})$. Among 13 patients who had abnormal ultrasound scan of kidneys, five were hypertensive, five were both hypertensive and diabetic and three had neither of the two risk factors.

\section{Overall survival}

At the time of follow up after two years of the diagnosis of bilateral GPI in 16 patients by Tc-99m DTPA renogram 11 (68.8\%) patients (seven male and four female) were found to be alive. Ten out of 11 patients who were alive reported to experience improvement of health as well as quality of life in comparison to two years past status. Principal working diagnoses at the time of Tc-99m DTPA renogram among these 10 patients were CKD in nine and moderate to gross dilatation of bilateral pelvicalyceal system in one. Four out of 11 was hypertensive while another four had both hypertension and diabetes; the remaining three patients had neither of the two risk factor. Out of 11 patients who were alive, one patient reported deterioration of quality of life as she had been experiencing progressive impairment of renal function accompanied by unsatisfactory control of diabetes and hypertension.

During the interval between diagnosis of bilateral gross GPI by Tc-99m DTPA renogram and follow up telephonic interview there were deaths of five (all male) out of $16(31.2 \%)$ patients. All deaths occurred in patients who were hospitalized with a primary aim of management for progressive renal functional impairment. One among these five patients had marked dilatation of bilateral pelvicalcyceal systems as his principal working diagnosis and another patient was suffering from nephrotic syndrome; these two had neither hypertension nor diabetes. For other three, CKD was a principal working diagnosis; in addition one patient had both hypertension and diabetes; the second patient was hypertensive only and the remaining patient had neither of those co morbidities.

Among the five deceased, two survived for 15 months, two survived for 12 months and the other one for about three weeks. Thus, in these study patients, one and two year survival was estimated to be 93.8 and $68.8 \%$. Overall mean survival in this patient group was $19.9 \pm$ 6.9 months (SE 1.67, 95\% CI 16.62 - 23.19).

One patient who was alive and reported progressive impairment of renal function had a rise of serum creatinine level to 4.2 from $2.9 \mathrm{mg} / \mathrm{dl}$ during two year follow up. Among the five deceased, four patients were on medical management while one was undergoing maintenance dialysis after imaging Improvement with therapy was noted in 10 patients. On the two year follow up, these patients reported a subjective improvement of health as well as quality of life and a decline of their mean serum creatinine level 
from $2.8 \pm 1.7 \mathrm{mg} / \mathrm{dl}$ to $1.5 \pm 0.3 \mathrm{mg} / \mathrm{dl}$ (mean difference $1.3 \pm 1.6$ ). A one tailed paired samples $t$ test found this difference (SE $0.51,95 \%$ CI 0.12 2.42) to be significant, $t=2.49, p=0.017$. Nine of these 10 patients stated that they were under medical management with dietary modification. The remaining one patient reported that she underwent stenting in renal artery in less than a month after the Tc-99m DTPA renogram.

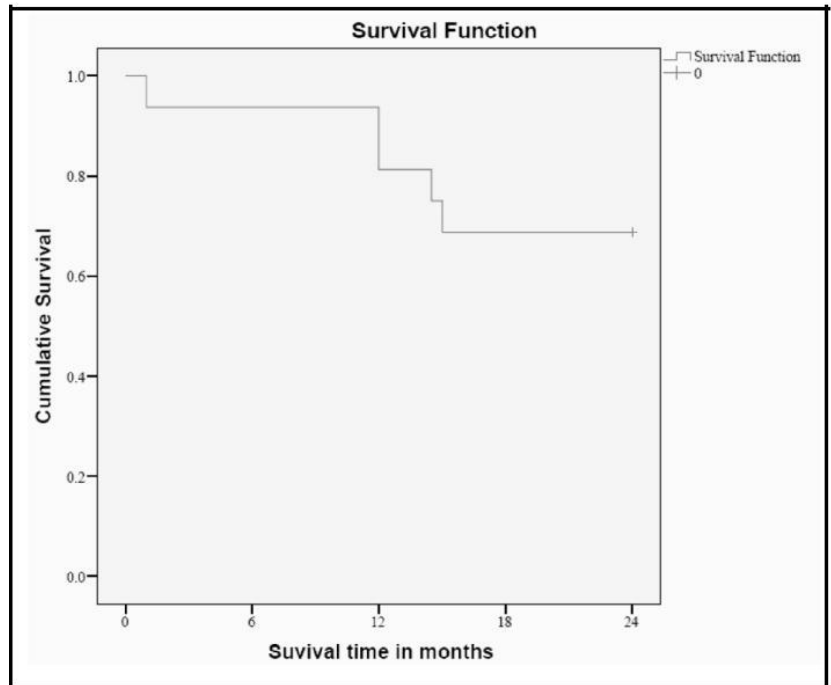

Figure 1. Kaplan-Meier survival plot of overall rates of survival in patients with bilateral gross renal parenchymal impairment diagnosed by Tc-99m DTPA renogram.

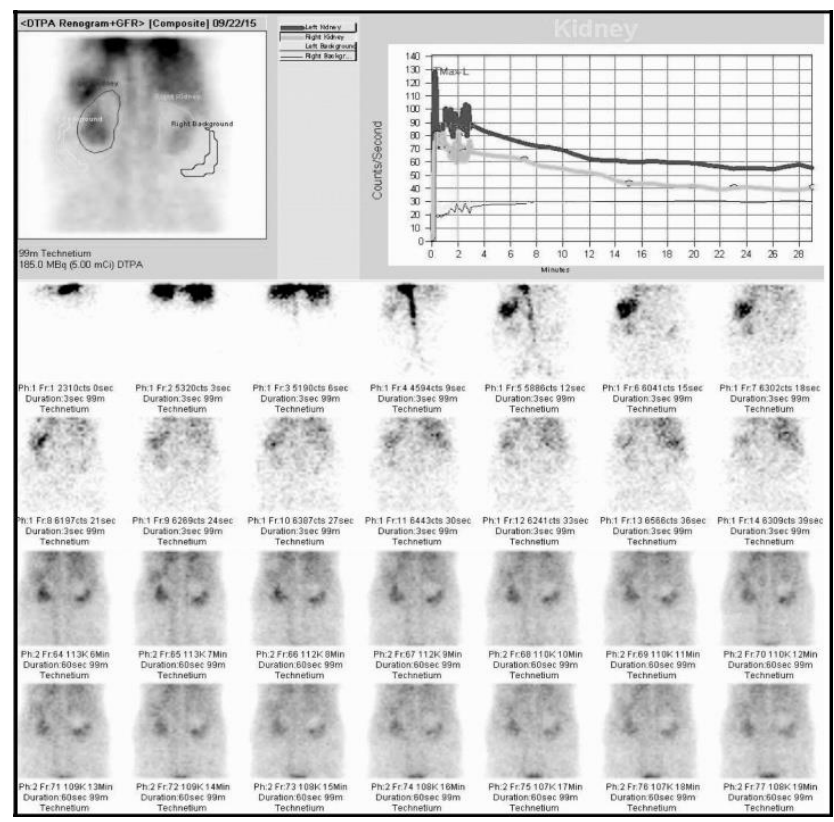

Figure 2. Representative time activity curves and images of Tc-99m DTPA renogram in an adult patient with bilateral gross renal parenchymal impairment.

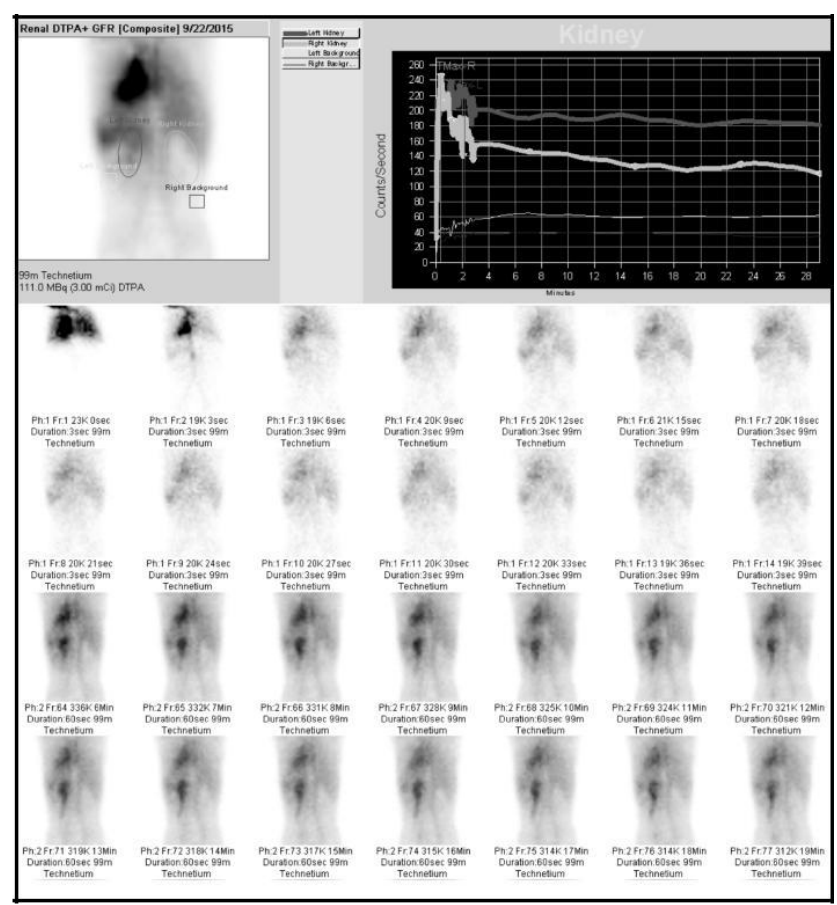

Figure 3. Representative time activity curves and image of Tc-99m DTPA renogram in a pediatric patient with bilateral gross renal parenchymal impairment.

\section{DISCUSSION}

Renal radionuclide scan has a long reputed role in the diagnostic and prognostic evaluation in renal dysfunctions. AKI and CKD are two different sets of conditions and can arise as a sequel of a wide range of pathologies. However both are not mutually exclusive and serve as reciprocal risk factors for each other (14). While AKI is a sudden onset reversible loss of kidney function which can sometimes be fatal, CKD refers to an irreversible deterioration in renal function developing over a considerable period viz. years (15). While serum level of creatinine is a mainstay of workup of AKI, the clinical interest to renal radionuclide scan in workup of AKI is to check for the renal blood flow and tubular function (16). Documentation of glomerular filtration rate (GFR) reduction in two different measurements done 3 months apart is a central marker for workup of CKD (15). The clinical point of renal radionuclide scan in management of CKD is to screen for renal artery stenosis and to estimate differential renal contribution to total GFR (17). In both cases a bilateral GPI 
revealed by renal radionuclide scan translates to worst prognosis in need of aggressive management.

Several cross sectional studies that were conducted in heterogeneous adult Bangladeshi population report the prevalence of chronic kidney disease from as low as $9.9 \%$ to as high as $26 \%$. $(10,11,12,18,19,20)$. Hospital reports show renal or genitourinary diseases were associated with 2.29 and $1.08 \%$ of all hospital deaths in 451 and 910 government health facilities in the years 2011 and 2012. (21, 22). The current study from a tertiary referral center has found the prevalence of severe forms of renal impairment, bilateral GPI to be $3.6 \%$ in the referred patients. There was a proportion of loss to follow-up and finally $76 \%$ patients were available for follow up. Our study further found that patients with bilateral GPI irrespective of their diagnoses survive for a mean period of 19.9 months (one and two year survival rate is 93.8 and 68.8\%). These findings are comparable with a study done in USA where one and two years survival rates of 80 and $67 \%$ were reported in patients newly diagnosed with ESRD and requiring dialysis (23). An interesting finding by Eriksen et al. is the slower decline in GFR with better patient and renal survival in patients of female gender compared to the male gender (24). Similarly in the current study, all four patients with increased survival were also of the female gender.

The current study has several limitations. While CKD is a risk factor for cardiovascular diseases, infections and cancer as well as ESRD (25), mortality in ESRD patients are also influenced by high baseline prevalence of diabetes mellitus and cardiovascular disease (26, 27 , $28,29,30)$. Small sample size of our study didn't allow the statistical tests to determine the relative risk from possible factors viz. age, sex, modes of management and presence of other co morbidities. Effect of patient compliance to treatment advises and assessment of death certificates was not possible. In addition this study didn't take into account the difference of survival in different stages of CKD and in different histopathological diagnoses.

\section{CONCLUSION}

Our data indicates long-term survival can be expected for most patients after nuclear imaging diagnosis of bilateral GPI with current modes of management available in our country. Conservative management with drugs and dietary modification seems to have positive impact on prognosis if the patient is compliant. Further observation in larger population over longer time frame is recommended for better assessment of survival pattern in kidney diseases in Bangladesh.

\section{Acknowledgement}

Authors are indebted to the Research and Development Division of NINMAS for the overall support and to the staffs from all Divisions of Nuclear Imaging at NINMAS for their efforts in data collection.

\section{REFERENCES}

1. Pannu N, James M, Hemmelgarn BR, Dong J, Tonelli M, Klarenbach S. Modification of Outcomes After Acute Kidney Injury by the Presence of CKD. Am J Kidney Dis. 2011; 58(2):206-213.

2. Uchino S, Kellum JA, Bellomo R, Doig GS, Morimatsu $\mathrm{H}$, Morgera $\mathrm{S}$, et al. Acute renal failure in critically ill patients: a multinational, multicenter study. JAMA. 2005; 294(7): 813-818.

3. Goldberg R, Dennen P. Long-term outcomes of acute kidney injury. Adv Chronic Kidney Dis. 2008; 15(3):297307.

4. United States Renal Data System. 2013 Annual Data Report. Available at http://www.usrds.org/adr.aspx. Accessed: Dec 6, 2015.

5. Collins AJ, Foley RN, Chavers B, Gilbertson D, Herzog C, Johansen K et al. United States Renal Data System USRDS 2011 Annual Data Report: Atlas of chronic kidney disease and end-stage renal disease in the United States. Am J Kidney Dis. 2012; 59 (1 Suppl 1): e1-420.

6. Bailie GR, Uhlig K, Levey AD. Clinical practice guidelines in nephrology: evaluation, classification, and stratification of chronic kidney disease. Pharmacotherapy. 2005 Apr; 25(4):491-502.

7. Cruz MC, Andrade C, Urrutia M, Draibe S, NogueiraMartins LA, Sesso R. Quality of life in patients with chronic kidney disease. Clinics 2011; 66(6): 991-995. 
8. Wang AY, Bellomo R, Cass A, Finfer S, Gattas D, Myburgh $\mathrm{J}$, et al. Health-related quality of life in survivors of acute kidney injury: The Prolonged Outcomes Study of the Randomized Evaluation of Normal versus Augmented Level Replacement Therapy study outcomes. Nephrology (Carlton). 2015; 20 (7):492-98.

9. World Health Organization - Noncommunicable Diseases (NCD) Country $\quad$ Profiles, 2014 http://www.who.int/nmh/countries/bgd_en.pdf. Accessed: Dec 6, 2015.

10. Rashid HU. Health delivery system for renal disease care in Bangladesh. Saudi J Kidney Dis Transpl. 2004;15 (2):185-89.

11. Alam KS, Huda MN, Rashid HU, Saha M. Prevalence of diabetes mellitus, hypertension, proteinuria and association of these risk factors with estimated glomerular filtration rate (eGFR) in adult disadvantaged population. Bangladesh Renal J 2010; 29(1): 1-6.

12. Faroque MO, Rashid HU, Rahman MH, Alam MR, Islam S. Prevalence of diabetes mellitus, hypertension and proteinuria in a rural area of Bangladesh. Bangladesh Renal J 2010; 29(1): 7-11.

13. Hadiuzzaman KBM, Rahman HM, Alam MR, Munirunnessa, Faruque MO, Shaha AK et al. Prevalence of diabetes mellitus, hypertension, and proteinuria in adult health service providers. Bangladesh Renal Journal 2010; 29(1):12-15.

14. Clinical Trials and Studies, Chapter 1. In: Acton QA, editor. Acute Kidney Injury: New Insights for the Healthcare Professional. Scholarly Brief ed. Atlanta, Georgia: ScholarlyEditions, 2013: 4.

15. Kidney and urinary tract diseases, Chapter 7, In: Innes JA editor. Davidson's Essentials of Medicine. 2nd ed. Edinburgh: Elsevier, 2016: 170-71.

16. Workeneh BT, Agraharkar M \& Gupta R. Workup (2015). Acute Kidney Injury. Retrieved from: http://emedicine.medscape.com/ Accessed: Dec 6, 2015.

17. Arora P, Batuman V (Ed.). Workup (2015) Chronic Kidney Disease. Retrieved from: http://emedicine.medscape.com/ Accessed: Dec 6, 2015.

18. Anand S, Khanam MA, Saquib J, Saquib N, Ahmed T, Alam DS et al. High prevalence of chronic kidney disease in a community survey of urban Bangladeshis: a crosssectional study. Global Health. 2014;10: 9.

19. Das S, Dutta PK. Chronic kidney disease prevalence among health care providers in Bangladesh. Mymensingh Med J. 2010;19(3):415-421.

20. Karim A, Das D, Salahuddin M, Marjan GA, Islam MN, Shaha $\mathrm{AK}$ et al. Prevalence of microalbuminuria and overt proteinuria in hypertension and their relations with renal function in a rural population of Bangladesh. Bangladesh J Medicine 2013; 24: 59-64.

21. MOHFW Bangladesh. MIS DG Health Services, Mortality Profile Bangladesh 2011. Chapter 8, Page 88100, Health bulletin 2012 retrieved from http://www.dghs.gov.bd/ Accessed Nov 19, 2015.

22. MOHFW Bangladesh. MIS DG Health Services. Mortality Profile. Chapter 8, Page 54-60, Health bulletin 2013 retrieved from http://www.dghs.gov.bd/ Accessed Nov 19, 2015.

23. Blaser R, Provenzano R. The Medicare Quality Improvement Act. Program and abstracts of the Kidney disease Economics Conference; February 4-6, 2005; Phoenix, Arizona.

24. Eriksen BO, Ingerbretsen OC. The progression of chronic kidney disease: A 10-year population-based study of the effects of gender and age. Kidney Int. 2006; 69: 375-382.

25. Levey AS, Atkins R, Coresh J, Cohen EP, Collins AJ, Eckardt $\mathrm{KU}$ et al. Chronic kidney disease as a global public health problem: approaches and initiatives-a position statement from kidney disease improving global outcomes. Kidney Int. 2007; 72(3): 247-259.

26. U.S. Renal Data System 1992 Annual Report: IV. Comorbid conditions and correlations with mortality risk among 3,399 incident hemodialysis patients. Am J Kid Dis. 1992; (Suppl 2):32-38.

27. Raine AE, Margreiter R, Brunner FP, Ehricfi JFI, Geerlings N, Landais $\mathrm{P}$ et al. Combined report on regular dialysis and transplantation in Europe, XXII. Nephrol Dial Transplant. 1992; 7(Suppl 2):7-35.

28. Hutchinson TA, Thomas CD, Macgibbon B. Predicting survival in adults with end-stage renal failure: An ageequivalence index. Ann Intern Med. 1982; 22:153-158.

29. Churchill DN, Taylor DW, Cook RJ, LA Plante P, Cartier P, Fay WP et al. Canadian hemodialysis morbidity study. Am J Kidney Dis. 1992; 19:214-234.

30. Foley RN, Parfrey PS, Hefferton D, Singh I, Simms A, Barrett BJ. Advance prediction of early death in patients starting maintenance dialysis. Am J Kid Dis. 1994; 23:836-45. 